\title{
Article
}

\section{Qualitative exploration of the views of healthy living champions from pharmacies in England.}

Rutter, Paul and Vryaparj, G

Available at http://clok.uclan.ac.uk/14205/

Rutter, Paul and Vryaparj, G (2015) Qualitative exploration of the views of healthy living champions from pharmacies in England. International Journal of Clinical Pharmacy, 37 (1). pp. 27-30. ISSN 2210-7703

It is advisable to refer to the publisher's version if you intend to cite from the work. http://dx.doi.org/10.1007/s11096-014-0055-2

For more information about UCLan's research in this area go to http://www.uclan.ac.uk/researchgroups/ and search for <name of research Group>.

For information about Research generally at UCLan please go to http://www.uclan.ac.uk/research/

All outputs in CLoK are protected by Intellectual Property Rights law, including Copyright law. Copyright, IPR and Moral Rights for the works on this site are retained by the individual authors and/or other copyright owners. Terms and conditions for use of this material are defined in the policies page.

\section{CLoK}

Central Lancashire online Knowledge www.clok.uclan.ac.uk

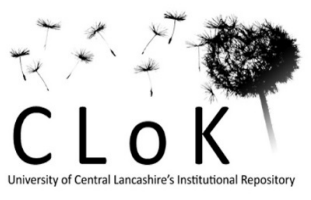


Qualitative exploration of the views of Healthy Living Champions from

3 Introduction

4 Self-care is an important element of patient care and has become prominent

5 in global health policy, [1-3] with community pharmacists identified as an

6 accessible professional group that can facilitate patient self-care - combining

7 traditional medicine supply with greater involvement in providing public health

8 services. [4-6]

9 In 2009, a UK based initiative, known as Healthy Living Pharmacies (HLP)

10 was piloted in Portsmouth (on the south coast of England). Its remit was to

11 deliver population-wide interventions to maximise patient self-care. A HLP

12 framework was designed and developed around a tiered commissioning

13 framework delivering health and wellbeing services tailored to local

14 requirements. The framework built on the nationally commissioned community

15 pharmacy contract by providing three levels of increasing sophistication of

16 service provision from level one to three, underpinned by a set of three

17 'enablers' to effect sustainable change, one of which was workforce

18 development. This included providing additional training to any member of

19 existing staff, other than the pharmacist, to become a healthy living champion

20 (HLC). Once qualified the HLC takes a lead role in delivering HLP services

21 such as smoking cessation, alcohol intervention and weight management.

22 Ideally, the HLC should live in the community that they work in. 
25 Preliminary findings from the Portsmouth study were positive and the

26 Department of Health cascaded the model nationally in 20 locations across

27 England. [7] The final findings from Portsmouth supported early findings but

28 highlighted success was dependent on achieving the right staff skill mix,

29 including the need for HLCs. [8]

30

31 Aim

32 The aim of the study was to understand the HLCs' perspective of their role

33 and to explore the barriers and facilitators to their performance.

34

35

36 Ethical Approval

37 This study was assessed by The School of Applied Sciences Ethics

38 Committee at Wolverhampton University and approved (BSEC 12/12/12).

39

40

41

42

43

44

45

46

47

48

49 
Method

51 At the time of the study, thirty pharmacies (from 67) had been accredited as

52 HLPs in the health boundary of NHS Dudley. Each pharmacy had one trained

53 HLC. Every HLC $(n=30)$ was written to and asked to take part in a semi-

54 structured face-to-face interview. Interviews were performed by GV at the

55 HLCs place of work. The interview schedule was developed by GV in 56 conjunction with the community pharmacy development officer (MD).

57 Questions were open-ended with additional prompts that explored HLCs 58 reasons for taking on this new role, their experiences so far and the facilitators 59 or barriers in fulfilling their duties. The interview schedule was piloted on two 60 qualified HLCs working from pharmacies that had still to gain accreditation as 61 functioning HLPs. The pilot showed that minor changes to wording were 62 required to aid clarity and facilitated an interview of approximately 20 minutes' 63 duration. These pilot data were not included in the results. Interviews took 64 place between February and March 2013. Interviews were audio recorded 65 and transcribed verbatim. Nvivo software (QSR International Pty Ltd, UK) was used to manage the data and content analysis was used to establish 67 any emergent themes; these were validated for context and understanding by 68 a second member of the research team (PR). With regard to researcher bias 69 and reflexivity, the interviewer (GV) was not employed by NHS Dudley and 70 had no relationship to any of the pharmacies or staff where interviews were 71 conducted. GV also kept a research diary through the process to raise 72 awareness of influences on data interpretation. 
Results

Fourteen interviews took place; one person had relinquished their role, six were either on holiday, sick or maternity leave. The remainder declined the opportunity to be interviewed. All HLCs were women and had been an HLC between six and twelve months. Coding produced three meta-themes; job

81 role, training and public awareness. Job role was constructed from the subordinate themes of: roles and responsibilities; motivation; satisfaction and personal benefit. HLCs spoke about personal betterment being a key driver

84 for them to take on the role. Interviewees spoke of 'greater opportunities', and 85 the ability to do 'different things'. All HLCs spoke with enthusiasm about their new role and gaining personal satisfaction from helping patients, which was reinforced through positive patient feedback. Below comments typify this:

"I do like it when you can help someone and they really appreciate it, that is a fantastic feeling." (HLC 1)

"I feel like I can make a difference to somebody and help to prevent them going into hospital in the first place...it makes me feel good about myself that I

94 can actively help someone." (HLC 8)

95

96 "I do enjoy helping them and the most part I enjoy is when they come back 97 and thank me... makes me feel I have helped somebody in my role as I am 98 supposed to." (HLC 4) 
100 With regard to training, sub themes of confidence and support were

101 identified. It was clear from interviewees that the role had allowed them to

102 gain new knowledge, with HLCs being much more confident in their own

103 ability:

104

105 "I have more confidence to deliver the service and talk to patients about stuff

106 you wouldn't have...I have been taught ways to communicate more

107 confidently." (HLC 9)

108

109 'I feel more confident as a person as people can approach me and ask me

110 questions... I feel like I have more knowledge that I can add to all my counter

111 and dispensing training...feel like I have something extra to offer.' (HLC 2)

113 Despite HLCs identifying that their confidence had improved as a result of the

114 training, they still had reservations over delivering services such as alcohol

115 and obesity services. HLCs were keen to receive further training and on-going

116 support as there was a general feeling that they wanted to keep up-to-date

117 and ensure new skills did not 'lapse'.

118

119 HLCs voiced concern about the public's general low level of awareness HLPs

120 and the services on offer despite acknowledgment that NHS Dudley had

121 promoted the HLP concept and HLPs had displays and signage to advertise

122 this. Typical comments illustrating this point were: 
125 “I still don't think the local community know that we are an HLP." (HLC 14)

126

127 "Patients do not know about HLPs...it needs to be put out across in a wider

128 scale about what healthy living pharmacies are because that may encourage

129 people to seek us. " (HLC 1)

130

131

132

133

134

135

136

137

138

139

140

141

142

143

144

145

146

147

148

149 
152 The HLP concept is an attempt to embed public health services alongside

153 traditional pharmacy functions and represents a new model of care delivery.

154 Evidence shows that adoption and delivery of innovative new community

155 pharmacy services is highly dependent on motivated individuals and teams [9-

156 10] This study therefore sought to understand the views of HLCs and explore

157 the barriers and facilitators to their performance - as the HLP concept

158 acknowledges that HLCs are central to effect sustainable change the delivery

159 of public health services. Our findings highlight HLCs held very positive views

160 toward their new role and were motivated through a sense of personal

161 development and a desire to want to help people; a sense of personal reward

162 being evident rather than financial gain. The change of status appeared to be

163 welcomed by HLCs, and helped them to talk with patients in a way that they

164 probably would have not done so before. This enabled HLCs to gain greater

165 job satisfaction through helping patients. These findings echo those seen in

166 the Portsmouth data [8]. However, unlike the Portsmouth data, it was

167 apparent from HLCs in Dudley that they had grown in confidence, which was

168 underpinned by the training and support received. Training undertaken clearly

169 facilitated their transition to an HLC yet when delivering certain services

170 (alcohol awareness and obesity), they found it challenging to engage with

171 patients and identified that further training and on-going support was required.

172 Further work on the mechanism of support to HLCs is needed to firstly

173 maintain competency and secondly to improve skills and confidence to allow

174 all (and potentially future) services to be delivered. 
175 A major barrier to the success of HLPs appears to be public engagement.

176 HLCs reported low public awareness of HLP services and is consistent with

177 pilot and pathfinder findings. [7, 11] Recent research suggests that community

178 pharmacy has the potential to deliver public health services, although the

179 impact on public health may be limited due to negative public (and health

180 provider) perceptions toward community pharmacy. [12]

181

182 The HLP model has does offer a way in which community pharmacy can

183 contribute to patient care in a formally recognised and remunerated way.

184 Evaluation to date has been generally positive both from a provider and user

185 perspective. Such a model could be used by other countries with similar

186 health policy and primary care networks. However, sustainability has yet to be

187 demonstrated in the HLP model and this work suggests that HLCs will be key

188 to long-term success. Support networks between HLCs need to be put in

189 place that are self-monitoring but require additional formal in put to maintain

190 and improve skills in delivering services.

191

192

193

194

195

196

197

198

199 
202 Only 14 of the 29 currently employed HLCs were interviewed and it is 203 unknown if those unwilling to be interviewed would have given the same 204 viewpoints; self-selection bias is therefore possible. Within the 14 interviews 205 conducted, data saturation could not be guaranteed as new themes were still 206 coming to light in the latter interviews, although these were infrequent and all 207 major themes had been identified by interview eight. In addition, this work was 208 conducted in just one of the 20 sites in England and therefore data must be 209 seen in this context and not necessarily representative of other areas. Despite 210 these limitations findings do highlight that staff can be trained to delivery

211 public health services to local communities and results in a motivated 212 workforce.

214 Conclusion

216 HLCs in NHS Dudley were motivated, enthusiastic and derived job

217 satisfaction from helping people to improve their health. Training provided

218 facilitated the transition to HLC but on-going training and support is needed to 219 ensure HLCs are able to continue in this role. 
1. Department of Health 2010 Healthy Lives, Healthy People: Our strategy for public health in England. ISBN: 9780101798525. http://www.official-

documents.gov.uk/document/cm79/7985/7985.pdf Accessed 28 November 2014.

2. Commonwealth of Australia. Building a 21st Century Primary Health Care System: Australia's First National Primary Health Care Strategy. Canberra, ACT: Department of Health and Ageing, 2010. ISBN: $174186934 X$

http://www.mmgpn.org.au/media/download gallery/COAG\%202011 \%20Communique\%20re\%20Health\%20Reform.pdf. Accessed 3 December 2014.

3. 2012 - the NZ Health Strategy, Health Targets, Better Sooner More convenient. ISBN 9780478374773 http://www.health.govt.nz/system/files/documents/publications/bette r-sooner-more-convenient-health-care $0 . p d f$. Accessed 3 December 2014. 
4. Department of Health. Pharmacy in England: building on strengths delivering the future. London: Department of Health 2008. ISBN 9780101734127. http://webarchive.nationalarchives.gov.uk/20130107105354/http://w ww.official-documents.gov.uk/document/cm73/7341/7341.pdf. Accessed 28 November 2014.

5. Canadian Pharmacists Association Task Force on a Blueprint for Pharmacy. Blueprint for Pharmacy: Designing the Future Together. Ottawa: CPhA, 2008.

http://www.pharmacists.ca/index.cfm/pharmacy-in-canada/blueprintfor-pharmacy/. Accessed 3 December 2014. Ten-year Vision for Pharmacists in New Zealand 2004-2014. Wellington: Pharmaceutical Society of New Zealand, 2004. http://psnz.org.nz/public/home/documents/10 yea plan.pdf. Accessed 3 December 2014.

7. NHS Portsmouth. An interim report on the outcomes from the Portsmouth Health Living Pharmacy initiative.

http://www.portsmouthcitypct.nhs.uk/Downloads/General\%20Docu ments/Portsmouth\%20HLP\%20interim\%20outcomes.pdf. Accessed 4 December 2014.

8. Brown D, Portlock J, Rutter P. From Community Pharmacy to Healthy Living Pharmacy: Early Experiences from Portsmouth, England. Res Social Adm Pharm. 2014;10(1):72-87. 
9. Tann J, Blenkinsopp A. Innovation in Community Pharmacy: Accelerating the Spread of Change. London: The Pharmacy Practice Research Trust, 2004.

http://www.natpact.info/uploads/innovation\%20briefing\%20\%20final.pdf. Accessed 28 November 2014.

10. Willink DP, Isetts BJ. Becoming 'indispensable': developing innovative community pharmacy practices. J Am Pharm Assoc. 2005;45(3):376-386. Pharm Pract. 2013; 21 (Suppl 2): 121.

12. Saramunee K, Krska J, Mackeridge A, Richards J, Suttajit S, Phillips-Howard P. How to enhance public health service utilization in community pharmacy?: general public and health providers' perspectives. Res Social Adm Pharm. 2014; 10: 272-84

11. Kennington E, Shepherd E, Evans D, Duggan C. Public experiences of healthy living pharmacies across England. Int $\mathrm{J}$ 
298

299

300

301

302

303

304

305

306

307 